\title{
Author Index Volume 32 (2013)
}

The issue number is given in front of the pagination

Achiron, A., see Kalron, A. (4) 943-948

Agarwal, N., C. Sarris, D.R. Hansberry, M.J. Lin, J.C. Barrese and C.J. Prestigiacomo, Quality of patient education materials for rehabilitation after neurological surgery (4) 817-821

Alderman, N., and R.L. Wood, Neurobehavioural approaches to the rehabilitation of challenging behaviour (4) 761-770

Alhusaini, A.A., see Ibrahim, A.I. (3) 563-571

Aligene, K., and E. Lin, Vestibular and balance treatment of the concussed athlete (3) 543-553

Aligene, K., see Lin, E. (3) 529-542

Alimovic, S., see Katusic, A. (1) 1-8

Al-Jarrah, M., H. Obaidat, Z. Bataineh, L. Walton and A. Al-Khateeb, Endurance exercise training protects against the upregulation of nitric oxide in the striatum of MPTP/probenecid mouse model of Parkinson's disease (1) 141-147

Al-Khateeb, A., see Al-Jarrah, M. (1) 141-147

Amatachaya, S., see Kumban, W. (1) 9-15

Ambrose, A., see Hirshson, C.I. (2) 225-232

Amonn, F., J. Frölich, D. Breuer, T. Banaschewski and M. Doepfner, Evaluation of a computerbased neuropsychological training in children with Attention-Deficit Hyperactivity Disorder (ADHD) (3) 555-562

An, D.-H., see Hwang, Y.-I. (2) 317-322

An, D.-H., see Hwang, Y.-I. (2) 377-383

Anderson, N.D., see Krpan, K.M. (4) 721-728

Arango-Lasprilla, J.C., see Perrin, P.B. (3) 679-686

Araújo, J.F., see Cavalcanti, P.R.A. (2) 337-343

Argolo, N., M. Sampaio, P. Pinho, A. Melo and A.C. Nóbrega, Do swallowing exercises improve swallowing dynamic and quality of life in Parkinson's disease? (4) 949-955

Aubut, J., see McIntyre, A. (2) 409-414

Aubut, J.-A.L., S. Marshall, M. Bayley and R.W. Teasell, A comparison of the PEDro and Downs and Black quality assessment tools using the acquired brain injury intervention literature (1) 95-102
Babinsky, R., see Leifert-Fiebach, G. (1) 43-58

Back, C.G.N., P.C.O. Benedini-Elias, S.M. Mattiello, C. Sobreira, E.Z. Martinez and A.C. MattielloSverzut, Change in the contractile behavior of muscle fibers in subjects with primary muscle dysfunction (3) 601-608

Bahrami, H., see Nejati, V. (2) 297-303

Baker, F.A., see Tamplin, J. (4) 929-941

Balconi, M., Inhibition of monitoring mechanisms in response to erroneous or veridical feedback. "Virtual lesion" induction by an rTMS study (4) 823-831

Banaschewski, T., see Amonn, F. (3) 555-562

Bang, Y.-I., K. Min, Y.H. Sohn and S.-R. Cho, Acoustic characteristics of vowel sounds in patients with Parkinson disease (3) 649-654

Barrese, J.C., see Agarwal, N. (4) 817-821

Barrett, R., see Dijkers, M. (2) 233-252

Barwood, C.H.S., B.E. Murdoch, S. Riek, J.D. O'Sullivan, A. Wong, D. Lloyd and A. Coulthard, Long term language recovery subsequent to low frequency rTMS in chronic non-fluent aphasia (4) 915-928

Bataineh, Z., see Al-Jarrah, M. (1) 141-147

Bayley, M., see Aubut, J.-A.L. (1) 95-102

Bellomo, R.G., see Di Pancrazio, L. (4) 855-860

Benedini-Elias, P.C.O., see Back, C.G.N. (3) 601-608

Berenji, G.R., see Mendez, M.F. (2) 397-407

Beschin, N., see Facchin, A. (4) 839-853

Bifolchetti, S., see Di Pancrazio, L. (4) 855-860

Bigler, E.D., K.O. Yeates, M. Dennis, C.A. Gerhardt, K.H. Rubin, T. Stancin, H.G. Taylor and K. Vannatta, Neuroimaging and social behavior in children after traumatic brain injury: Findings from the Social Outcomes of Brain Injury in Kids (SOBIK) study (4) 707-720

Bilik, M., see Mirowska-Guzel, D. (3) 573-582

Bonanni, L., see Di Pancrazio, L. (4) 855-860

Brandstater, M., see Dijkers, M. (2) 233-252

Brandt, T., see Leifert-Fiebach, G. (1) 43-58

Breuer, D., see Amonn, F. (3) 555-562 
Cabrera, T.V., see Perrin, P.B. (3) 679-686

Caldwell, S.B., see McGuinness, S. (3) 635-647

Calis, F.A., A.Y. On and B. Durmaz, Validity and reliability of a new test for Turkish-speaking aphasic patients: Ege Aphasia Test (1) 157-163

Campos, T.F., see Cavalcanti, P.R.A. (2) 337-343

Cantor, J., see Hirshson, C.I. (2) 225-232

Cantor, J.B., W. Gordon and S. Gumber, What is post TBI fatigue? (4) 875-883

Carroll, A., see Jones, C. (2) 351-358

Cavalcanti, P.R.A., T.F. Campos and J.F. Araújo, Circadian and homeostatic changes of sleep-wake and quality of life in stroke: Implications for neurorehabilitation (2) 337-343

Cha, Y.-J., and H. Kim, Effect of computer-based cognitive rehabilitation (CBCR) for people with stroke: A systematic review and meta-analysis (2) 359-368

Chandrasekhar, S.S., The assessment of balance and dizziness in the TBI patient (3) 445-454

Chang, C.H., see Kwon, H.G. (1) 27-32

Chang, P.-H., see Yeo, S.S. (4) 861-866

Chang, R., see Khan, S. (3) 437-443

Chen, I.J., see Cheng, S.P. (4) 967-976

Chen, L., see Jin, H. (2) 327-335

Chen, M.-C., see Tsai, P.-L. (1) 33-42

Cheng, S.P., C.Y. Yang, F.I. Tang and I.J. Chen, Training effects of a 12-week walking program on Parkinson disease patients and communitydwelling older adults (4) 967-976

Cho, K.H., see Lee, N.G. (1) 17-26

Cho, S.-R., see Bang, Y.-I. (3) 649-654

Choi, B.Y., see Kwon, H.G. (1) 27-32

Choi, J.-S., see Kim, H.-S. (3) 687-692

Choi, M.-H., see Kim, H.-S. (3) 687-692

Choi, Y.W., see Kwon, J.W. (1) 191-196

Choi, Y.W., see Lee, N.K. (2) 385-390

Chrzastowski, C., see Combs, S.A. (1) 117-124

Chung, S.-C., see Kim, H.-S. (3) 687-692

Chung, Y.-S., see Kim, H.-S. (3) 687-692

Cisari, C., see Facchin, A. (4) 839-853

Cohen, A.H., Vision rehabilitation for visual-vestibular dysfunction: The role of the neuro-optometrist (3) 483-492

Combs, S.A., M.D. Diehl, C. Chrzastowski, N. Didrick, B. McCoin, N. Mox, W.H. Staples and J. Wayman, Community-based group exercise for persons with Parkinson disease: A randomized controlled trial (1) 117-124

Copley, J., K. Kuipers, J. Fleming and M. Rassafiani, Individualised resting hand splints for adults with acquired brain injury: A randomized, single blinded, single case design (4) 885-898

Coulthard, A., see Barwood, C.H.S. (4) 915-928

Crane, P.K., see Gavett, B.E. (2) 253-265

Culver, C., see Dams-O'Connor, K. (2) 199-209

Czlonkowska, A., see Mirowska-Guzel, D. (3) 573-582

Czlonkowski, A., see Mirowska-Guzel, D. (3) 573-582

D’Andreagiovanni, A., see Di Pancrazio, L. (4) 855-860 da Silva Ramos, S., see Oddy, M. (4) 781-790

Daini, R., see Facchin, A. (4) 839-853

Dams-O'Connor, K., L. Spielman, F.M. Hammond, N. Sayed, C. Culver and R. Diaz-Arrastia, An exploration of clinical dementia phenotypes among individuals with and without traumatic brain injury (2) 199-209

Dams-O'Connor, K., see Gavett, B.E. (2) 253-265

Dams-O'Connor, K., see Hirshson, C.I. (2) 225-232

Dams-O'Connor, K., see Yi, A. (2) 267-273

de Morton, N., see Johnston, M. (4) 957-966

Dennis, M., see Bigler, E.D. (4) 707-720

Dettmers, C., see Hilgers, C. (3) 655-663

Di Pancrazio, L., R.G. Bellomo, R. Franciotti, P. Iodice, V. Galati, A. D’Andreagiovanni, S. Bifolchetti, A. Thomas, M. Onofrj, L. Bonanni and R. Saggini, Combined rehabilitation program for postural instability in progressive supranuclear palsy (4) 855-860

Diaz-Arrastia, R., see Dams-O’Connor, K. (2) 199-209

Dick, J.P.R., see Poliakoff, E. (1) 125-134

Didrick, N., see Combs, S.A. (1) 117-124

Diehl, M.D., see Combs, S.A. (1) 117-124

Dijkers, M., M. Brandstater, S. Horn, D. Ryser and R. Barrett, Inpatient rehabilitation for traumatic brain injury: The influence of age on treatments and outcomes (2) 233-252

Dijkers, M., see Hirshson, C.I. (2) 225-232

Doepfner, M., see Amonn, F. (3) 555-562

Domen, K., see Koyama, T. (1) 87-94

Durmaz, B., see Calis, F.A. (1) 157-163

Eichstaedt, K.E., K. Kovatch and D.A. Maroof, A less conservative method to adjust for familywise error rate in neuropsychological research: The Holm's sequential Bonferroni procedure (3) 693-696

Emasithi, A., see Kumban, W. (1) 9-15

Facchin, A., N. Beschin, A. Toraldo, C. Cisari and R. Daini, Aftereffect induced by prisms of different power in the rehabilitation of neglect: A multiple single case report (4) 839-853 
Fayaz, R.K., see Jijimol, G. (2) 323-325

Feng, J., see Zhang, J. (2) 391-396

Fleming, J., see Copley, J. (4) 885-898

Foy, C.M.L., and J.S. Somers, Increase in functional abilities following a residential educational and neurorehabilitation programme in young adults with acquired brain injury (3) 671-678

Franceschini, M., see Tavernese, E. (3) 591-599

Franciotti, R., see Di Pancrazio, L. (4) 855-860

Frölich, J., see Amonn, F. (3) 555-562

Fu, H., see Zhang, J. (2) 391-396

Galati, V., see Di Pancrazio, L. (4) 855-860

Galatioto, J.A., see Lei-Rivera, L. (3) 463-472

Galpin, A.J., see Poliakoff, E. (1) 125-134

Gan, C., see Moreno, J.A. (1) 69-85

Gavett, B.E., P.K. Crane and K. Dams-O'Connor, Bifactor analyses of the Brief Test of Adult Cognition by Telephone (2) 253-265

Gay, R.K., Neurocognitive measures in the assessment of vestibular disturbance in patients with brain injury (3) 473-482

Gelav, S., see Kalron, A. (4) 943-948

Gerhardt, C.A., see Bigler, E.D. (4) 707-720

Ghasia, F.F., see Shaikh, A.G. (3) 493-505

Godbee, K., see Tate, R.L. (4) 729-750

Gordon, W., see Cantor, J.B. (4) 875-883

Gordon, W.A., see Hirshson, C.I. (2) 225-232

Greenberg-Abrahami, M., see Kalron, A. (4) 943-948

Greisberger, A., see Kiselka, A. (2) 415-423

Gromadzka, G., see Mirowska-Guzel, D. (3) 573-582

Gruchala, K., see Mirowska-Guzel, D. (3) 573-582

Gumber, S., see Cantor, J.B. (4) 875-883

Guo, X., see Waldman, G. (3) 625-634

Gurley, J.M., B.D. Hujsak and J.L. Kelly, Vestibular rehabilitation following mild traumatic brain injury (3) 519-528

Gurley, J.M., see Lei-Rivera, L. (3) 463-472

Hadoush, H., H. Mano, T. Sunagawa, K. Nakanishi and M. Ochi, Optimization of mirror therapy to excite ipsilateral primary motor cortex (3) 617-624

Hammond, F.M., see Dams-O’Connor, K. (2) 199-209

Han, B.S., see Lee, J.J. (2) 279-285

Hansberry, D.R., see Agarwal, N. (4) 817-821

Harding, K., see Johnston, M. (4) 957-966

Harvey, R.L., see Waldman, G. (3) 625-634

Hawamdeh, Z.M., see Ibrahim, A.I. (3) 563-571

Hayes, S., see Poliakoff, E. (1) 125-134

Hegazy, F.A., see Ibrahim, A.I. (3) 563-571

Heller, M., see Kiselka, A. (2) 415-423
Heo, H.-J., see Hwang, Y.-I. (2) 377-383

Hilgers, C., A. Mündermann, H. Riehle and C. Dettmers, Effects of whole-body vibration training on physical function in patients with Multiple Sclerosis (3) 655-663

Hillan, J., see McGuinness, S. (3) 635-647

Hirshson, C.I., W.A. Gordon, A. Singh, A. Ambrose, L. Spielman, K. Dams-O'Connor, J. Cantor and M. Dijkers, Mortality of elderly individuals with TBI in the first 5 years following injury (2) 225232

Hong, S.-P., see Kim, H.-S. (3) 687-692

Horn, S., see Dijkers, M. (2) 233-252

Huang, Y.-T., see Tsai, P.-L. (1) 33-42

Hujsak, B.D., see Lei-Rivera, L. (3) 463-472

Hujsak, B.D., see Gurley, J.M. (3) 519-528

Hwang, P.W., see Lee, J.A. (2) 287-295

Hwang, Y.-I., W.-G. Yoo and D.-H. An, Effects of the Elastic Walking Band on gait in stroke patients (2) 317-322

Hwang, Y.-I., W.-G. Yoo, D.-H. An and H.-J. Heo, The effect of an AFO-shaped elastic band on drop-foot gait in patients with central neurological lesions (2) 377-383

Hyun You (Joshua), S., see Lee, J.J. (2) 279-285

Hyun You (Sung), J., see Lee, N.G. (1) 17-26

Ibrahim, A.I., A.A. Alhusaini, F.A. Hegazy and Z.M. Hawamdeh, Effectiveness of foot wedge and carrying weighted bag on loading the paretic lower limb in children with hemiparetic cerebral palsy (3) 563-571

Iodice, P., see Di Pancrazio, L. (4) 855-860

Jang, S.H., Motor function-related maladaptive plasticity in stroke: A review (2) 311-316

Jang, S.H., see Jo, H.M. (2) 369-375

Jang, S.H., see Kim, E.H. (3) 583-590

Jang, S.H., see Kwon, H.G. (1) 27-32

Jang, S.H., see Yeo, S.S. (2) 305-309

Jang, S.H., see Yeo, S.S. (3) 665-669

Jang, S.H., see Yeo, S.S. (4) 861-866

Janzen, S., see McIntyre, A. (2) 409-414

Jeong, S.J., see Lee, N.G. (1) 17-26

Jiang, Y., see Jin, H. (2) 327-335

Jijimol, G., R.K. Fayaz and P.V. Vijesh, Correlation of trunk impairment with balance in patients with chronic stroke (2) 323-325

Jimenez-Maldonado, M., see Perrin, P.B. (3) 679-686

Jin, H., Y. Jiang, Q. Wei, L. Chen and G. Ma, Effects of aerobic cycling training on cardiovascular fitness 
and heart rate recovery in patients with chronic stroke (2) 327-335

Jo, H.M., J.-c. Song and S.H. Jang, Improvements in spasticity and motor function using a static stretching device for people with chronic hemiparesis following stroke (2) 369-375

Jo, U., see Kim, S.J. (1) 185-190

Joa, K.-L., see Kim, D.H. (4) 833-838

Johnston, M., N. de Morton, K. Harding and N. Taylor, Measuring mobility in patients living in the community with Parkinson disease (4) 957-966

Jones, B., see Tamplin, J. (4) 929-941

Jones, C., K. O'Keeffe, C. Kingston and A. Carroll, Alleviating psychosocial issues for individuals with communication impairments and their families following stroke: A case series of interdisciplinary assessment and intervention (2) 351-358

Jung, M.-y., see Yoo, I.-g. (3) 609-615

Jung, Y.J., see Kwon, H.G. (1) 27-32

Kalron, A., M. Greenberg-Abrahami, S. Gelav and A. Achiron, Effects of a new sensory re-education training tool on hand sensibility and manual dexterity in people with multiple sclerosis (4) 943948

Katusic, A., S. Alimovic and V. Mejaski-Bosnjak, The effect of vibration therapy on spasticity and motor function in children with cerebral palsy: A randomized controlled trial (1) 1-8

Kellett, M., see Poliakoff, E. (1) 125-134

Kelly, J.L., see Gurley, J.M. (3) 519-528

Kemmer, T.P., see Schorl, M. (1) 149-156

Khan, S., and R. Chang, Anatomy of the vestibular system: A review (3) 437-443

Kieffer-Kristensen, R., V.D. Siersma and T.W. Teasdale, Family matters: Parental-acquired brain injury and child functioning (1) 59-68

Kim, C.S., see Kwon, J.W. (1) 191-196

Kim, C.S., see Lee, N.K. (2) 385-390

Kim, D.A., see Lee, J.A. (2) 287-295

Kim, D.H., Y.-I. Shin, K.-L. Joa, Y.K. Shin, J.J. Lee and S.H. You, Immediate effect of Walkbot robotic gait training on neuromechanical knee stiffness in spastic hemiplegia: A case report (4) 833-838

Kim, E.H., J. Lee and S.H. Jang, Motor outcome prediction using diffusion tensor tractography of the corticospinal tract in large middle cerebral artery territory infarct (3) 583-590

Kim, H., see Cha, Y.-J. (2) 359-368

Kim, H.-J., see Kim, H.-S. (3) 687-692

Kim, H.-K., see Lee, J.A. (2) 287-295
Kim, H.-S., M.-H. Choi, H.-J. Kim, H.-W. Yeon, H.-J. Yoon, I.-H. Lee, S.-P. Hong, N.-R. Yu, J.-S. Choi, J.-H. Yi, Y.-S. Chung, D.-W. Lim and S.-C. Chung, Changes in simple visual matching task performance and physiological signals in intellectually and developmentally disabled people due to administration of highly concentrated oxygen (3) 687-692

Kim, H.-s., see Yoo, I.-g. (3) 609-615

Kim, S.H., see Kwon, H.G. (1) 27-32

Kim, S.H., see Yeo, S.S. (3) 665-669

Kim, S.J., and U. Jo, Study of accent-based music speech protocol development for improving voice problems in stroke patients with mixed dysarthria (1) $185-190$

Kimelman, M.D.Z., see Wallace, S.E. (4) 899-913

Kingston, C., see Jones, C. (2) 351-358

Kiselka, A., A. Greisberger and M. Heller, Perception of muscular effort in multiple sclerosis (2) 415423

Kong, K.-H., and J. Lee, Temporal recovery and predictors of upper limb dexterity in the first year of stroke: A prospective study of patients admitted to a rehabilitation centre (2) 345-350

Kovatch, K., see Eichstaedt, K.E. (3) 693-696

Koyama, T., K. Marumoto, H. Miyake, T. Ohmura and K. Domen, Relationship between diffusion-tensor fractional anisotropy and long-term outcome in patients with hemiparesis after intracerebral hemorrhage (1) 87-94

Krpan, K.M., N.D. Anderson and D.T. Stuss, Obstacles to remediating coping following traumatic brain injury (4) 721-728

Kuipers, K., see Copley, J. (4) 885-898

Kumban, W., S. Amatachaya, A. Emasithi and W. Siritaratiwat, Five-times-sit-to-stand test in children with cerebral palsy: Reliability and concurrent validity (1) 9-15

Kwon, H.G., B.Y. Choi, C.H. Chang, S.H. Kim, Y.J. Jung and S.H. Jang, Recovery of an injured corticospinal tract during a critical period in a patient with intracerebral hemorrhage (1) 27-32

Kwon, J.W., S.H. Nam, N.K. Lee, S.M. Son, Y.W. Choi and C.S. Kim, The effect of transcranial direct current stimulation on the motor suppression in stop-signal task (1) 191-196

Kwon, J.W., see Lee, N.K. (2) 385-390

Lasprilla, J.C.A., see Moreno, J.A. (1) 69-85

Lee, D.R., see Lee, J.A. (2) 287-295

Lee, D.R., see Lee, J.J. (2) 279-285 
Lee, I.-H., see Kim, H.-S. (3) 687-692

Lee, J., see Kim, E.H. (3) 583-590

Lee, J., see Kong, K.-H. (2) 345-350

Lee, J., see Yoo, I.-g. (3) 609-615

Lee, J.A., J.H. You, D.A. Kim, M.J. Lee, P.W. Hwang, N.G. Lee, J.J. Park, D.R. Lee and H.-K. Kim, Effects of functional movement strength training on strength, muscle size, kinematics, and motor function in cerebral palsy: A 3-month follow-up (2) $287-295$

Lee, J.J., D.R. Lee, Y.K. Shin, N.G. Lee, B.S. Han and S. (Joshua) Hyun You, Comparative neuroimaging in children with cerebral palsy using fMRI and a novel EEG-based brain mapping during a motor task - A preliminary investigation (2) 279-285

Lee, J.J., see Kim, D.H. (4) 833-838

Lee, M.J., see Lee, J.A. (2) 287-295

Lee, N.G., S.J. Jeong, J. (Sung) Hyun You, K.H. Cho and T.H. Lee, Effects of the progressive walking-torunning technique on gait kinematics, ultrasound imaging, and motor function in spastic diplegic cerebral palsy - an experimenter-blind case study (1) $17-26$

Lee, N.G., see Lee, J.A. (2) 287-295

Lee, N.G., see Lee, J.J. (2) 279-285

Lee, N.K., J.W. Kwon, S.M. Son, S.H. Nam, Y.W. Choi and C.S. Kim, Changes of plantar pressure distributions following open and closed kinetic chain exercise in patients with stroke (2) 385-390

Lee, N.K., see Kwon, J.W. (1) 191-196

Lee, S., see Tamplin, J. (4) 929-941

Lee, T.H., see Lee, N.G. (1) 17-26

Leifert-Fiebach, G., A. Welfringer, R. Babinsky and T. Brandt, Motor imagery training in patients with chronic neglect: A pilot study (1) 43-58

Lei-Rivera, L., J. Sutera, J.A. Galatioto, B.D. Hujsak and J.M. Gurley, Special tools for the assessment of balance and dizziness in individuals with mild traumatic brain injury (3) 463-472

Lesniak, M., see Mirowska-Guzel, D. (3) 573-582

Lewis, F.M., and B.E. Murdoch, Differential language trajectories following treatment for pediatric posterior fossa tumor: An investigation of four cases (1) 165-183

Liang, L.-J., see Mendez, M.F. (2) 397-407

Licht, E.A., see Mendez, M.F. (2) 397-407

Lim, D.-W., see Kim, H.-S. (3) 687-692

Lin, E., and K. Aligene, Pharmacology of balance and dizziness (3) 529-542

Lin, E., see Aligene, K. (3) 543-553

Lin, K.-C., see Tsai, P.-L. (1) 33-42
Lin, M.J., see Agarwal, N. (4) 817-821

Liu, L., see Waldman, G. (3) 625-634

Lloyd, D., see Barwood, C.H.S. (4) 915-928

Ma, G., see Jin, H. (2) 327-335

Man, D.W.K., see Yip, B.C.B. (1) 103-115

Mandic, V., see Tavernese, E. (3) 591-599

Mangone, M., see Tavernese, E. (3) 591-599

Mano, H., see Hadoush, H. (3) 617-624

Maroof, D.A., Examining and reporting the status of statistical assumptions in neuropsychological research: A misbegotten ethical obligation? (2) 275-278

Maroof, D.A., see Eichstaedt, K.E. (3) 693-696

Marshall, S., see Aubut, J.-A.L. (1) 95-102

Martinez, E.Z. see Back, C.G.N. (3) 601-608

Martinez-Cortes, M.L., see Perrin, P.B. (3) 679-686

Marumoto, K., see Koyama, T. (1) 87-94

Mattiello, S.M., see Back, C.G.N. (3) 601-608

Mattiello-Sverzut, A.C., see Back, C.G.N. (3) 601-608

McCoin, B., see Combs, S.A. (1) 117-124

McDonald, K., see Poliakoff, E. (1) 125-134

McGuinness, S., J. Hillan and S.B. Caldwell, Botulinum toxin in gait dysfunction due to ankle clonus: A case series (3) 635-647

McIntyre, A., S. Mehta, S. Janzen, J. Aubut and R.W. Teasell, A meta-analysis of functional outcome among older adults with traumatic brain injury (2) 409-414

McKerral, M., see Moreno, J.A. (1) 69-85

McMillan, T.M., Outcome of rehabilitation for neurobehavioural disorders (4) 791-801

Mehta, S., see McIntyre, A. (2) 409-414

Mejaski-Bosnjak, V., see Katusic, A. (1) 1-8

Melo, A., see Argolo, N. (4) 949-955

Mendez, M.F., E.M. Owens, G.R. Berenji, D.C. Peppers, L.-J. Liang and E.A. Licht, Mild traumatic brain injury from primary blast vs. blunt forces: Post-concussion consequences and functional neuroimaging (2) 397-407

Min, K., see Bang, Y.-I. (3) 649-654

Mirowska-Guzel, D., G. Gromadzka, J. Seniow, M. Lesniak, M. Bilik, K. Waldowski, K. Gruchala, A. Czlonkowski and A. Czlonkowska, Association between BDNF-196 $\mathrm{G}>\mathrm{A}$ and $B D N F-270 \mathrm{C}>\mathrm{T}$ polymorphisms, BDNF concentration, and rTMSsupported long-term rehabilitation outcome after ischemic stroke (3) 573-582

Miyake, H., see Koyama, T. (1) 87-94

Moreno, J.A., J.C.A. Lasprilla, C. Gan and M. McKerral, Sexuality after traumatic brain injury: A critical review (1) 69-85 
Mox, N., see Combs, S.A. (1) 117-124

Müller, T., and A. Pietsch, Comparison of gait training versus cranial osteopathy in patients with Parkinson's disease: A pilot study (1) 135-140

Mündermann, A., see Hilgers, C. (3) 655-663

Murdoch, B.E., see Barwood, C.H.S. (4) 915-928

Murdoch, B.E., see Lewis, F.M. (1) 165-183

Nakanishi, K., see Hadoush, H. (3) 617-624

Nam, S.H., see Kwon, J.W. (1) 191-196

Nam, S.H., see Lee, N.K. (2) 385-390

Nejati, V., H.R. Pouretemad and H. Bahrami, Attention Training in rehabilitation of children with developmental stuttering (2) 297-303

Nóbrega, A.C., see Argolo, N. (4) 949-955

O’Keeffe, K., see Jones, C. (2) 351-358

O'Sullivan, J.D., see Barwood, C.H.S. (4) 915-928

Obaidat, H., see Al-Jarrah, M. (1) 141-147

Ochi, M., see Hadoush, H. (3) 617-624

Oddy, M., and S. da Silva Ramos, Cost effective ways of facilitating home based rehabilitation and support (4) $781-791$

Oh, D.-W., and H.-J. Park, One-year follow-up of the effects of community-based ambulation training for ambulatory patients with incomplete spinal cord injury: A case series (2) 425-432

Ohmura, T., see Koyama, T. (1) 87-94

On, A.Y., see Calis, F.A. (1) 157-163

Onofrj, M., see Di Pancrazio, L. (4) 855-860

Owens, E.M., see Mendez, M.F. (2) 397-407

Paoloni, M., see Tavernese, E. (3) 591-599

Park, H.-J., see Oh, D.-W. (2) 425-432

Park, J.-h., see Yoo, I.-g. (3) 609-615

Park, J.J., see Lee, J.A. (2) 287-295

Park, S.-h., see Yoo, I.-g. (3) 609-615

Peppers, D.C., see Mendez, M.F. (2) 397-407

Perrin, P.B., L.F. Stevens, T.V. Cabrera, M. JimenezMaldonado, M.L. Martinez-Cortes and J.C. Arango-Lasprilla, Just how bad is it? Comparison of the mental health of Mexican traumatic brain injury caregivers to age-matched healthy controls (3) 679-686

Pietsch, A., see Müller, T. (1) 135-140

Pinho, P., see Argolo, N. (4) 949-955

Poliakoff, E., A.J. Galpin, K. McDonald, M. Kellett, J.P.R. Dick, S. Hayes and A.J. Wearden, The effect of gym training on multiple outcomes in Parkinson's disease: A pilot randomised waitinglist controlled trial (1) 125-134
Ponsford, J., Factors contributing to outcome following traumatic brain injury (4) 803-815

Pouretemad, H.R., see Nejati, V. (2) 297-303

Prestigiacomo, C.J., see Agarwal, N. (4) 817-821

Prigatano, G.P., Challenges and opportunities facing holistic approaches to neuropsychological rehabilitation (4) 751-759

Radziszewski, K., Outcomes of electrical stimulation of the neurogenic bladder: Results of a two-year follow-up study (4) 867-873

Rassafiani, M., see Copley, J. (4) 885-898

Ren, Y., see Waldman, G. (3) 625-634

Riehle, H., see Hilgers, C. (3) 655-663

Riek, S., see Barwood, C.H.S. (4) 915-928

Rine, R.M., and S. Wiener-Vacher, Evaluation and treatment of vestibular dysfunction in children (3) 507-518

Roth, E.J., see Waldman, G. (3) 625-634

Rubin, K.H., see Bigler, E.D. (4) 707-720

Ruff, R., Selecting the appropriate psychotherapies for individuals with traumatic brain injury: What works and what does not? (4) 771-779

Ryser, D., see Dijkers, M. (2) 233-252

Saggini, R., see Di Pancrazio, L. (4) 855-860

Sale, P., see Tavernese, E. (3) 591-599

Sampaio, M., see Argolo, N. (4) 949-955

Santilli, V., see Tavernese, E. (3) 591-599

Sarris, C., see Agarwal, N. (4) 817-821

Sayed, N., see Dams-O'Connor, K. (2) 199-209

Schorl, M., S.J. Valerius-Kukula and T.P. Kemmer, Critical-Illness-Polyneuropathy as sequelae of severe neurological illness: Incidence and impact on ventilator therapy and rehabilitation (1) 149156

Seniow, J., see Mirowska-Guzel, D. (3) 573-582

Shaikh, A.G., and F.F. Ghasia, Physiology and pathology of saccades and gaze holding (3) 493-505

Shin, Y.-I., see Kim, D.H. (4) 833-838

Shin, Y.K., see Kim, D.H. (4) 833-838

Shin, Y.K., see Lee, J.J. (2) 279-285

Siersma, V.D., see Kieffer-Kristensen, R. (1) 59-68

Sigmundsdottir, L., see Tate, R.L. (4) 729-750

Singh, A., see Hirshson, C.I. (2) 225-232

Siritaratiwat, W., see Kumban, W. (1) 9-15

Smouha, E., Inner ear disorders (3) 455-462

Sobreira, C., see Back, C.G.N. (3) 601-608

Sohn, Y.H., see Bang, Y.-I. (3) 649-654

Somers, J.S., see Foy, C.M.L. (3) 671-678

Son, S.M., see Kwon, J.W. (1) 191-196 
Son, S.M., see Lee, N.K. (2) 385-390

Song, J.-c., see Jo, H.M. (2) 369-375

Spielman, L., see Dams-O'Connor, K. (2) 199-209

Spielman, L., see Hirshson, C.I. (2) 225-232

Stancin, T., see Bigler, E.D. (4) 707-720

Staples, W.H., see Combs, S.A. (1) 117-124

Stevens, L.F., see Perrin, P.B. (3) 679-686

Stuss, D.T., see Krpan, K.M. (4) 721-728

Sunagawa, T., see Hadoush, H. (3) 617-624

Sutera, J., see Lei-Rivera, L. (3) 463-472

Tamplin, J., F.A. Baker, B. Jones, A. Way and S. Lee, 'Stroke a Chord': The effect of singing in a community choir on mood and social engagement for people living with aphasia following a stroke (4) $929-941$

Tang, F.I., see Cheng, S.P. (4) 967-976

Tate, R.L., K. Godbee and L. Sigmundsdottir, A systematic review of assessment tools for adults used in traumatic brain injury research and their relationship to the ICF (4) 729-750

Tavernese, E., M. Paoloni, M. Mangone, V. Mandic, P. Sale, M. Franceschini and V. Santilli, Segmental muscle vibration improves reaching movement in patients with chronic stroke. A randomized controlled trial (3) 591-599

Taylor, H.G., see Bigler, E.D. (4) 707-720

Taylor, N., see Johnston, M. (4) 957-966

Teasdale, T.W., see Kieffer-Kristensen, R. (1) 59-68

Teasell, R.W., see Aubut, J.-A.L. (1) 95-102

Teasell, R.W., see McIntyre, A. (2) 409-414

Thomas, A., see Di Pancrazio, L. (4) 855-860

Toraldo, A., see Facchin, A. (4) 839-853

Tsai, P.-L., M.-C. Chen, Y.-T. Huang and K.-C. Lin, Effects of listening to pleasant music on chronic unilateral neglect: A single-subject study (1) 33-42

Valerius-Kukula, S.J., see Schorl, M. (1) 149-156

Vannatta, K., see Bigler, E.D. (4) 707-720

Victoroff, J., Traumatic encephalopathy: Review and provisional research diagnostic criteria (2) 211 224

Vijesh, P.V., see Jijimol, G. (2) 323-325

Waldman, G., C.-Y. Yang, Y. Ren, L. Liu, X. Guo, R.L. Harvey, E.J. Roth and L.-Q. Zhang, Effects of robot-guided passive stretching and active movement training of ankle and mobility impairments in stroke (3) 625-634

Waldowski, K., see Mirowska-Guzel, D. (3) 573-582
Wallace, S.E., and M.D.Z. Kimelman, Generalization of word retrieval following semantic feature treatment (4) 899-913

Walton, L., see Al-Jarrah, M. (1) 141-147

Way, A., see Tamplin, J. (4) 929-941

Wayman, J., see Combs, S.A. (1) 117-124

Wearden, A.J., see Poliakoff, E. (1) 125-134

Wei, Q., see Jin, H. (2) 327-335

Welfringer, A., see Leifert-Fiebach, G. (1) 43-58

Wiener-Vacher, S., see Rine, R.M. (3) 507-518

Wong, A., see Barwood, C.H.S. (4) 915-928

Wood, R.L., Recognising and assessing neurobehavioural disability after traumatic brain injury (4) 699706

Wood, R.L., see Alderman, N. (4) 761-770

Yang, C.Y., see Cheng, S.P. (4) 967-976

Yang, C.-Y., see Waldman, G. (3) 625-634

Yeates, K.O., see Bigler, E.D. (4) 707-720

Yeo, S.S., and S.H. Jang, Recovery of an injured corticospinal tract and an injured corticoreticular pathway in a patient with intracerebral hemorrhage (2) 305-309

Yeo, S.S., P.-H. Chang and S.H. Jang, The cortical activation differences between proximal and distal joint movements of the upper extremities: A functional NIRS study (4) 861-866

Yeo, S.S., S.H. Kim and S.H. Jang, Proximal weakness due to injury of the corticoreticular pathway in a patient with traumatic brain injury (3) 665-669

Yeon, H.-W., see Kim, H.-S. (3) 687-692

Yi, A., and K. Dams-O'Connor, Psychosocial functioning in older adults with Traumatic Brain Injury (2) 267-273

Yi, J.-H., see Kim, H.-S. (3) 687-692

Yin, C., see Zhang, J. (2) 391-396

Yip, B.C.B., and D.W.K. Man, Virtual reality-based prospective memory training program for people with acquired brain injury (1) 103-115

Yoo, E.-y., see Yoo, I.-g. (3) 609-615

Yoo, I.-g., M.-y. Jung, E.-y. Yoo, S.-h. Park, J.-h. Park, J. Lee and H.-s. Kim, Effect of specialized task training of each hemisphere on interlimb transfer in individuals with hemiparesis (3) 609-615

Yoo, W.-G., see Hwang, Y.-I. (2) 317-322

Yoo, W.-G., see Hwang, Y.-I. (2) 377-383

Yoon, H.-J., see Kim, H.-S. (3) 687-692

You, J.H., see Lee, J.A. (2) 287-295

You, S.H., see Kim, D.H. (4) 833-838

Yu, N.-R., see Kim, H.-S. (3) 687-692 
Zhang, J., C. Yin, Y. Zhang, L. Zhao, H. Fu and J. Feng, Zhang, L.-Q., see Waldman, G. (3) 625-634

The role of OLR1 polymorphisms in determining Zhang, Y., see Zhang, J. (2) 391-396

the risk and prognosis of ischemic stroke in a Zhao, L., see Zhang, J. (2) 391-396

Chinese population (2) 391-396 